\title{
Surfactant protein-A enhances respiratory syncytial virus clearance in vivo
}

\author{
Ann Marie LeVine, Jodie Gwozdz, James Stark, Michael Bruno, Jeffrey Whitsett, \\ and Thomas Korfhagen
}

Division of Pulmonary Biology, Children's Hospital Medical Center, Cincinnati, Ohio 45229-3039, USA

Address correspondence to: Ann Marie LeVine, Division of Pulmonary Biology, Children's Hospital Medical Center, 3333 Burnet Avenue, Cincinnati, Ohio 45229-3039, USA. Phone: (513) 636-4830; Fax: (513) 636-7868; E-mail: levia0@chmcc.org

Received for publication November 19, 1998, and accepted in revised form February 19, 1999.

\begin{abstract}
To determine the role of surfactant protein- $\mathrm{A}(\mathrm{SP}-\mathrm{A})$ in antiviral host defense, mice lacking SP-A (SP-A $\left.\mathrm{A}^{-/}\right)$ were produced by targeted gene inactivation. SP-A ${ }^{-/-}$and control mice $\left(\mathrm{SP}-\mathrm{A}^{+/+}\right)$were infected with respiratory syncytial virus (RSV) by intratracheal instillation. Pulmonary infiltration after infection was more severe in SP- $\mathrm{A}^{-/-}$than in SP- $\mathrm{A}^{+/+}$mice and was associated with increased $\mathrm{RSV}$ plaque-forming units in lung homogenates. Pulmonary infiltration with polymorphonuclear leukocytes was greater in the SP-A $\mathrm{A}^{-/-}$mice. Levels of proinflammatory cytokines tumor necrosis factor- $\alpha$ and interleukin- 6 were enhanced in lungs of SP-A $\mathrm{A}^{-/-}$mice. After RSV infection, superoxide and hydrogen peroxide generation was deficient in macrophages from SP-A $\mathrm{A}^{-/}$mice, demonstrating a critical role of SP-A in oxidant production associated with RSV infection. Coadministration of RSV with exogenous SP-A reduced viral titers and inflammatory cells in the lung of SP-A $\mathrm{A}^{-/-}$mice. These findings demonstrate that SP-A plays an important host defense role against RSV in vivo.
\end{abstract}

J. Clin. Invest. 103:1015-1021 (1999).

\section{Introduction}

Surfactant protein-A (SP-A) is a 28 - to $34-\mathrm{kDa}$ member of the collectin subgroup of the mammalian C-type lectins that also includes surfactant protein-D (SP-D), mannose-binding protein, and conglutinin $(1,2)$. The collectins are thought to be involved in innate host defense against various bacterial and viral pathogens. For example, children deficient in mannose-binding proteins are more susceptible to bacterial infection (3). The collectins form multimeric structures resembling $\mathrm{C} 1 \mathrm{q}$ (the first component of the complement cascade), consisting of multimeric collagenous $\mathrm{NH}_{2}$-terminal domains and globular $\mathrm{COOH}$-terminal, carbohydratebinding domains $(2,4)$. The C-type lectins bind carbohydrate surfaces of many microorganisms, mediating phagocytosis and killing by phagocytic cells (5-8).

SP-A is an abundant C-type lectin produced primarily by alveolar type II cells, nonciliated bronchiolar cells, and tracheobronchial gland cells in the lung. SP-A binds to specific cell-surface receptors on alveolar macrophages (9) and type II epithelial cells (10). In vitro, SP-A stimulates macrophage chemotaxis (11) and enhances the binding of serum-opsonized Staphylococcus aureus (12), non-serum-opsonized Escherichia coli, S. aureus, Hemophilus influenzae, and Mycobacterium tuberculosis to alveolar macrophages (13-15). SP-A also binds herpes simplex virus, herpes simplex virus-infected cells $(16,17)$, and influenza A virus $(18,19)$.

Respiratory syncytial virus (RSV) produces an upper respiratory tract disease that may progress to acute bronchiolitis or interstitial pneumonia. Approximately one in 100 children infected with RSV will require hospitalization (20); as many as $11 \%$ of hospitalized infants may require intensive care (21). Children with respiratory fail- ure from RSV bronchiolitis have decreased concentrations of SP-A in bronchoalveolar lavage (BAL) fluid (22, 23). Conditions predisposing to severe RSV disease include prematurity, bronchopulmonary dysplasia, congenital heart disease, congenital or acquired immunodeficiency, and cystic fibrosis - conditions that may also be associated with decreased SP-A in the lung (24-26).

Specific as well as nonspecific immune mechanisms take part in RSV immunity and probably also RSV pathogenesis. The specific immune response includes cytotoxic T cells and antibody production. Nonspecific immune responses include natural killer cells, macrophages, neutrophils, eosinophils, and basophils (27). Alveolar macrophages are thought to play a critical role in host defense of the lung. Alveolar macrophages bind, phagocytose, and kill bacteria and viruses in association with cellular activation and release of intracellular proteases and reactive oxygen species. Reactive oxygen species are released by activated alveolar macrophages and may contribute to killing of viruses (28). In vitro, SP-A directly stimulates lucigenin-dependent chemiluminescence (12) and produces a dosedependent enhancement of oxygen radical release from rat alveolar macrophages (29). In contrast, stimulated canine alveolar macrophages produce less superoxide anions in the presence of SP-A (30).

In spite of considerable in vitro evidence that SP-A is involved in host defense, its role in vivo has only recently been demonstrated. SP-A-deficient mice (SP-A-/-) produced by targeted gene inactivation are susceptible to group B streptococcal and Pseudomonas aeruginosa pneumonia after intratracheal administration of the organism $(31,32)$. Although there is compelling evidence that SP-A enhances host defense against viruses 

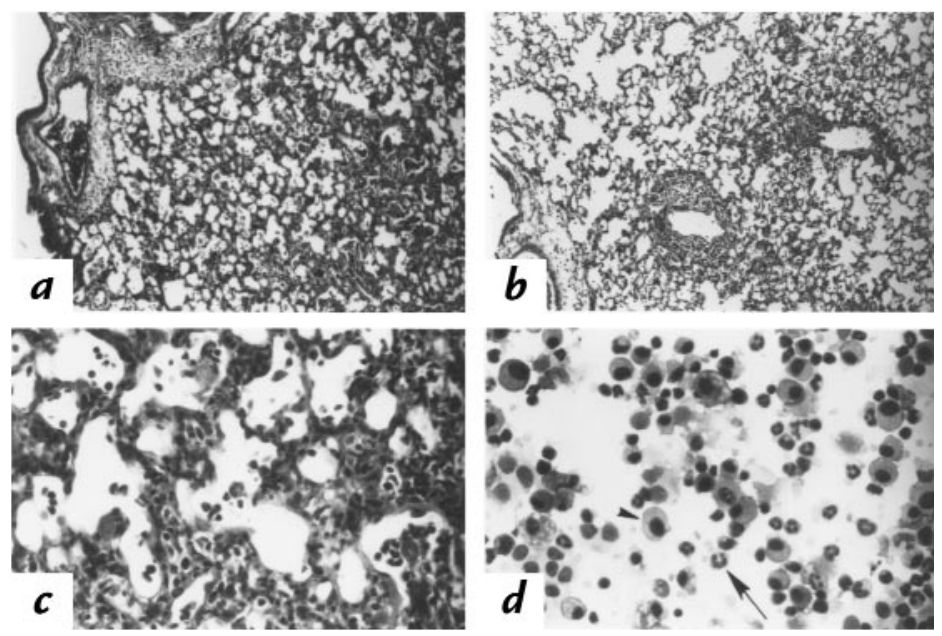

\section{Figure 1}

Pulmonary pathology after RSV infection. Photomicrographs of lung parenchyma in (a) $\mathrm{SP}_{-} \mathrm{A}^{-/-}$and $(\boldsymbol{b}) \mathrm{SP}^{-\mathrm{A}^{+/+}}$mice were prepared 7 days after intratracheal administration of $10^{7}$ pfu RSV. Histological sections were stained with hematoxylin and eosin. Infiltration was observed surrounding the terminal bronchi and pulmonaryvessels in the SP-A $\mathrm{A}^{--}$and SP-A $\mathrm{A}^{+/+}$mice. Higher magnification demonstrates infiltration with mononuclear cells and polymorphonuclear leukocytes in SP-A-/- mice (c). Cells from BAL consisted of mononuclear cells (arrowhead) and polymorphonuclear leukocytes (arrow) (d). $a$ and $b: \times 10 ; c$ and $d: \times 40 . B A L$, bronchoalveolar lavage; $p f u$, plaque-forming units; $R S V$, respiratory syncytial virus; $S P-A$, surfactant protein-A. in vitro, its role in the clearance of viral pathogens in vivo has not been demonstrated. The present study tested whether SP-A ${ }^{-1}$ mice had increased susceptibility to RSV infection in vivo.

\section{Methods}

Animal production. The murine SP-A gene was inactivated by gene targeting as described previously (33). Lungs of SP-A $\mathrm{A}^{-/}$mice do not contain detectable SP-A mRNA or protein (33). To limit variability related to strain differences, $129 \mathrm{~J}$ wild-type $(+/+)$ and SP$\mathrm{A}^{-/-}$mice of the same strain were studied. Animals were housed and studied under Institutional Animal Care and Use Committee-approved protocols in the animal facility of the Children's Hospital Research Foundation. Male and female mice weighing approximately $20-30 \mathrm{~g}$ (8-10 weeks old) were used.

Purification of human SP-A. Human SP-A obtained from patients with alveolar proteinosis was purified by the 1-butanol extraction method of Haagsman et al. (34). Purified SP-A was dissolved ( $2 \mathrm{mg} / \mathrm{ml}$ ) in NaHEPES ( $\mathrm{pH} 7.2)$ and tested with the Limulus Amoebocyte Lysate assay (Sigma Chemical Co., St. Louis, Missouri, USA) for endotoxin. SP-A used in the present study had no detectable endotoxin $(<0.06 \mathrm{EU} / \mathrm{ml})$.

Preparation of virus. HEp-2 cells were maintained in Eagle's minimal essential media (EMEM) supplemented with glutamine, amphotericin, streptomycin, penicillin G, and $10 \%$ lowimmunoglobulin FBS (10\% EMEM). The A2 strain of RSV was kindly supplied by B.S. Graham (Vanderbilt University, Nashville, Tennessee, USA). RSV was plaquepurified three times under agarose. The third plaque was inoculated into a subconfluent HEp-2 cell monolayer. After adsorption for $1 \mathrm{~h}$ at room temperature, $10 \%$ EMEM was added, and the infection was allowed to proceed for 3 days at $37^{\circ} \mathrm{C}$ until the entire monolayer showed cytopathic effects. The contents of the flask were resuspended and distributed in 1-ml aliquots, quick-frozen with alcohol/dry ice, and stored at $-80^{\circ} \mathrm{C}$. Working stocks were derived from this master stock by infecting subconfluent HEp-2 monolayers at a multiplicity of infection of 0.1 and harvesting the monolayer when it appeared to be completely infected. The cells and media $(50 \mathrm{ml})$ were sonicated (Ultrasonic homogenizer; Cole-Parmer Instrument Co., Chicago, Illinois, USA) on ice with eight 1-s bursts using an output of 50. The suspension was clarified by centrifugation at $1,800 \mathrm{~g}$ for $10 \mathrm{~min}$. The supernatant was quickfrozen and stored at $-80^{\circ} \mathrm{C}$.
Intratracheal inoculation. Administration of RSV into the respiratory tract of the mice was performed by intratracheal inoculation of $10^{6}$ or $10^{7}$ plaque-forming units (pfu) diluted in $10 \%$ EMEM. Intratracheal inoculation as described previously (31) was used to deliver RSV. Controls received sterile 10\% EMEM.

Viral clearance. Quantitative RSV cultures of lung homogenates were performed 3, 5, and 7 days after inoculation of the animals with RSV or RSV plus SP-A. Because previous studies demonstrated enhanced bacterial clearance in $\mathrm{SP}_{-} \mathrm{A}^{-/}$ mice with $100 \mu \mathrm{g}$ of SP-A (35), this dose was chosen for the present study. The entire lung was removed as described (31), homogenized in $2 \mathrm{ml}$ of sterile 10\% EMEM, quick-frozen, weighed, and stored at $-80^{\circ} \mathrm{C}$. HEp- 2 monolayers, $80 \%$ confluent in Costar 12-well plates, were used for the plaque assay.

Thawed tissues were clarified, serially diluted in $10 \%$ EMEM, plated on HEp-2 monolayer $(50 \mu \mathrm{l})$, and adsorbed for $1 \mathrm{~h}$, and $0.75 \%$ methylcellulose in $10 \%$ EMEM was added to each well. After 5 days at $37^{\circ} \mathrm{C}$, the monolayers were fixed with $10 \%$ formalin phosphate, stained with hematoxylin and eosin, and viral plaques were counted under a dissecting microscope. The resulting titer was divided by the lung weight and reported as pfu per gram of lung. Experiments comparing viral titers in whole lung from fresh and frozen tissue revealed a twofold reduction in pfu with freezing. Viral titers in the lung of SP-A-treated mice were assessed in fresh lung homogenates.

\section{Table 1}

Decreased superoxide and hydrogen peroxide production from alveolar macrophages of SP-A $\mathrm{A}^{-/-}$mice

$\begin{array}{lccc}\begin{array}{l}\text { Source of macrophages } \\ \text { (genotype) }\end{array} & \begin{array}{c}\text { Peak superoxide } \\ \text { radical }\end{array} & \begin{array}{c}\text { Peak hydrogen } \\ \text { peroxide } \\ \text { nmol cytochrome } c \text { reduced }\end{array} & \begin{array}{l}n \mathrm{M}) \\ \mathrm{SP}-\mathrm{A}^{+/+}\end{array} \\ {\mathrm{SP}-\mathrm{A}^{-/-}}^{2.96 \pm 1.1} & 15.0 \pm 3.9 & \\ & 0.28 \pm 0.2^{\mathrm{A}} & 2.0 \pm 0.5^{\mathrm{A}} & 6\end{array}$

Superoxide and hydrogen peroxide production were assessed in cells isolated from BAL fluid 3 days after intratracheal administration of RSV $\left(10^{6} \mathrm{pfu}\right)$. The reduction of cytochrome $c$ in the presence and absence of superoxide dismutase or catalase was measured from PMA-stimulated macrophages. Superoxide production was assessed by subtracting activity in the presence of superoxide dismutase, and hydrogen peroxide production was assessed by subtracting activity in the presence of catalase from total oxygen radical production. Hydrogen peroxide production by macrophages was also measured using the Bioxytech $\mathrm{H}_{2} \mathrm{O}_{2} 560$ assay, based on the oxidation of ferrous ions $\left(\mathrm{Fe}^{2+}\right)$ to ferric ions $\left(\mathrm{Fe}^{3+}\right)$ by hydrogen peroxide (data in table), with similar results as the reduction of cytochrome $c$ assay. Macrophages from $\mathrm{SP}-\mathrm{A}^{+/+}$mice generated significantly more superoxide and hydrogen peroxide than did macrophages from $\mathrm{SP}-\mathrm{A}^{-/-}$mice. Data are mean $\pm \mathrm{SEM}$ for the number of experiments. ${ }^{\mathrm{A}} \mathrm{P}<0.05$ compared with $\mathrm{SP}-\mathrm{A}^{+/+}$mice. $P M A$, phorbol myristate acetate. 


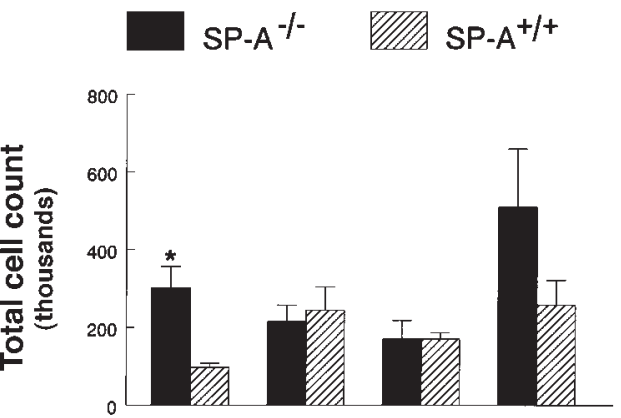

$\boldsymbol{b}$

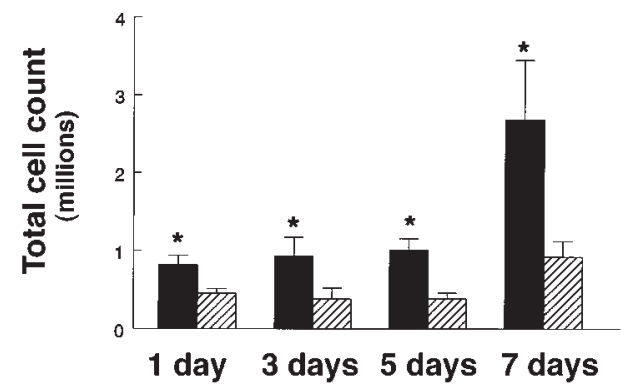

Figure 2

Increased total cell counts in BAL fluid from SP-A ${ }^{-/-}$mice. Lung cells were recovered by $B A L$, stained with trypan blue, and counted under light microscopy. (a) The low dose of RSV $\left(10^{6} \mathrm{pfu}\right)$ caused less migration of inflammatory cells in the lungs from both genotypes; however, an earlier influx of cells was found in SP-A-/- (filled bars) BAL fluid than in $\mathrm{SP}^{-\mathrm{A}^{+/+}}$ (hatched bars) mice. (b) SP-A $\mathrm{A}^{-/-}$mice infected with $10^{7} \mathrm{pfu}$ RSV had significantly greater total cell counts in BAL fluid at all time points. Data are mean \pm SEM with $n=5$ mice per group $(a)$ and $n=9$ mice per group $(b)$. ${ }^{*} P<0.05$ compared with SP-A $\mathrm{A}^{+/+}$mice.

Pulmonary pathology. Lungs were inflated via a tracheal cannula at $20 \mathrm{~cm}$ of pressure with $4 \%$ paraformaldehyde and removed en bloc from the thorax. Lungs were dehydrated and embedded in paraffin. Tissue sections $(5 \mu \mathrm{m})$ were stained with hematoxylin and eosin.

Bronchoalveolar lavage. Lung cells were recovered by bronchoalveolar lavage (BAL). Animals were sacrificed as described for viral clearance, and lungs were lavaged three times with $1 \mathrm{ml}$ of sterile PBS. The fluid was centrifuged at 2,000 $\mathrm{g}$ for $10 \mathrm{~min}$ and resuspended in $600 \mu \mathrm{l}$ of PBS, and total cells were stained with trypan blue and counted under light microscopy. Differential cell counts were performed on cytospin preparations stained with Diff-Quick (Scientific Products, McGaw Park, Indiana, USA).

Cytokine production. Lung homogenates were centrifuged at $2,000 \mathrm{~g}$, and the supernatants stored at $-20^{\circ} \mathrm{C}$. Tumor necrosis factor- $\alpha$ (TNF- $\alpha$ ), interleukin (IL)- $1 \beta$, IL- 6 , and macrophage inflammatory protein-2 (MIP-2) were quantitated using murine sandwich ELISA kits (R\&D Systems Inc., Minneapolis, Minnesota, USA) according to the manufacturer's directions. All plates were read on a microplate reader (Molecular Devices, Menlo Park, California, USA) and analyzed with the use of a computer-assisted analysis program (Softmax; Molecular Devices). Only assays having standard curves with a calculated regression line value $>0.95$ were accepted for analysis.

Superoxide anion generation. Superoxide anion and hydrogen peroxide production by alveolar macrophages was determined as described (36). Three days after intratracheal inoculation of RSV $\left(10^{6} \mathrm{pfu}\right)$, alveolar macrophages were collected by BAL with $3 \mathrm{ml}$ of dye-free RPMI media (GIBCO BRL, Grand Island, New York, USA). BAL fluid from six mice was pooled to provide suf- ficient numbers of macrophages for analysis. The lavage was centrifuged at $1,200 \mathrm{~g}$ for $10 \mathrm{~min}$, and the pellet resuspended in $200 \mu \mathrm{l}$ of PBS. One hundred thousand cells were placed in wells of a 96-well plate with $1.2 \mathrm{mg} / \mathrm{ml}(\sim 100 \mu \mathrm{mol} / \mathrm{l})$ cytochrome $c$, with or without $20 \mu \mathrm{g} / \mathrm{ml}$ superoxide dismutase or catalase (200 $\mathrm{U} / 10^{5}$ cells), in a final volume of $200 \mu \mathrm{l}$ of HBSS. Superoxide anion production was determined after activation with 100 $\mathrm{ng} / \mathrm{ml}$ phorbol myristate acetate (PMA). Optical density at 550 $\mathrm{nm}$ was determined using a THERMOmax microplate reader (Molecular Devices) linked to a laboratory computer. Measurements were made initially and at 5, 10, and $15 \mathrm{~min}$, then every 15 min until $2 \mathrm{~h}$ at $37^{\circ} \mathrm{C}$. Optical density was converted to nanomoles of cytochrome $c$ reduced using a molar extinction coefficient of $21.1 / \mathrm{mM} \cdot \mathrm{cm}$. Each measurement was the mean of at least two replicates with six determinations at each time. Data were expressed as nanomoles cytochrome $c$ reduced per $10^{5}$ cells. Superoxide production was assessed by subtracting activity in the presence of superoxide dismutase and hydrogen peroxide by subtracting activity in the presence of catalase from total oxygen radical production. Hydrogen peroxide production by macrophages was also measured using a commercially available assay (Bioxytech $\mathrm{H}_{2} \mathrm{O}_{2} 560$ assay; OXIS International, Portland, Oregon, USA) based on the oxidation of ferrous ions $\left(\mathrm{Fe}^{2+}\right)$ to ferric ions $\left(\mathrm{Fe}^{3+}\right)$ by hydrogen peroxide under acidic conditions. Methods followed the manufacturer's recommendations.

Statistical methods. Lung viral titers, total cell counts, and differential analysis were compared using the nonparametric Van der Waerden rank rest. Superoxide and hydrogen peroxide peak values were compared using the median scores nonparametric test. Comparisons among SP-A $\mathrm{A}^{-/}$and wild-type mice treated

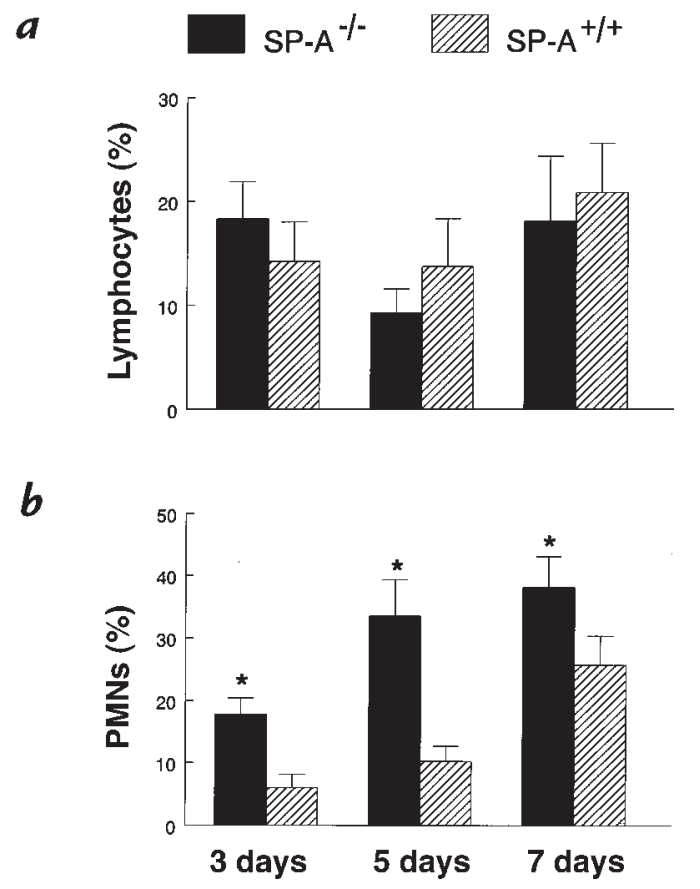

Figure 3

Increased neutrophils in BAL fluid from SP-A $/-$ mice after RSV infection. Cytospin preparations of BAL fluid were stained with Diff-Quik to identify macrophages, lymphocytes, and polymorphonuclear leukocytes. (a) The percentage of neutrophils in BAL fluid was significantly greater 3,5 , and 7 days after administration of $10^{7}$ pfu RSV to SP-A- - - (filled bars) compared with SP- $\mathrm{A}^{+/+}$(hatched bars) mice. (b) Percentages of lymphocytes in BAL fluid were not different between the two groups. Data are mean \pm SEM with $n=9$ mice per group. ${ }^{*} P<0.05$ compared with SP-A $A^{+/+}$mice. $P M N s$, polymorphonuclear leukocytes. 


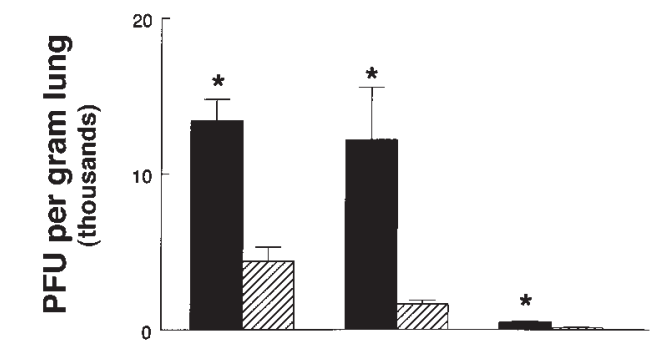

$b$

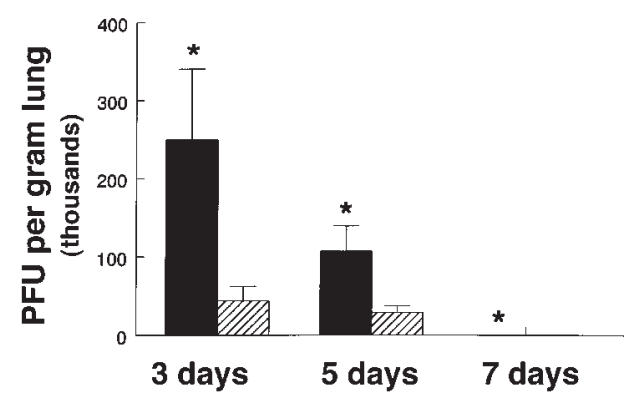

Figure 4

Increased RSV in lung homogenates from SP-A $\mathrm{A}^{-/-}$mice. RSV titers were determined by quantitative plaque assays of lung homogenates. Viral titers were significantly greater 3,5 , and 7 days after administration of both $10^{6}(\boldsymbol{a})$ and $10^{7}(\boldsymbol{b})$ pfu RSV in SP-A ${ }^{-/-}$( filled bars) compared with SP$\mathrm{A}^{+/+}$(hatched bars) mice. Data are mean \pm SEM with $n=6$ mice per group (a) and $n=10$ mice per group $(b) .{ }^{*} P<0.05$ compared with SP-A ${ }^{+/+}$mice.

with SP-A were performed with the least squared means model analysis. Findings were considered statistically significant at probability levels $<0.05$.

\section{Results}

Pulmonary pathology after RSV administration. The viral dose used in the current study was $10^{6}$ or $10^{7} \mathrm{pfu}$. This dose range has been shown to generate inflammation in the lungs of mice over a seven-day period without mortality (37). Intratracheal administration of RSV was well tolerated, and all animals survived the study period at the $10^{6}$ and $10^{7} \mathrm{pfu}$ dose. No alterations in activity or physical appearance of the animals were detected throughout the study.

Pulmonary infiltrates were observed in SP-A ${ }^{-/}$and $\mathrm{SP}-\mathrm{A}^{+/+}$mice five days after administration of $10^{7} \mathrm{pfu}$ RSV. The infiltrates consisted primarily of macrophages. In SP-A ${ }^{-/}$and $\mathrm{SP}-\mathrm{A}^{+/+}$mice, peribronchiolar, perivascular, and alveolar infiltrates consisting of macrophages and polymorphonuclear leukocytes were observed at seven days (Figure 1). Although the extent of pulmonary inflammation appeared similar by histological examination, three, five, and seven days after $10^{7} \mathrm{pfu}$ RSV, SP-A ${ }^{-/-}$mice had increased total cells counts in BAL fluid (Figure 2). Baseline total cell counts in BAL fluid from control $\left(\mathrm{SP}^{\left.-\mathrm{A}^{+/+}\right)}\right.$mice inoculated with sterile $10 \%$ EMEM were $1.4 \times 10^{5} \pm 1.4 \times 10^{4}$ (mean \pm SEM). A significantly greater percentage of polymorphonuclear leukocytes (PMNs) were detected in BAL fluid from $\mathrm{SP}_{-} \mathrm{A}^{-/-}$compared with $\mathrm{SP}-\mathrm{A}^{+/+}$mice at all time points. No differences were detected in percentages of lymphocytes (Figure 3). Pulmonary infiltrates were not observed in SP-A $\mathrm{A}^{+/+}$mice inoculated with sterile $10 \% \operatorname{EMEM}(n=5)$.

Decreased viral clearance in $S P-A^{-/-}$mice. Viral titers in lung homogenates were increased in SP-A $\mathrm{A}^{-/}$mice three, five, and seven days after infection (Figure 4). The difference in viral titers between SP-A ${ }^{-/-}$and SP-A $\mathrm{A}^{+/+}$mice was found with both the $10^{6}$ and $10^{7}$ pfu inoculum of RSV and was most evident at three and five days, indicating that RSV was cleared from the lungs of SP-A $\mathrm{A}^{-/}$ mice at a slower rate than from the lungs of SP-A ${ }^{+/+}$mice.

Cytokine levels in lung homogenates. Twenty-four hours after RSV infection, proinflammatory cytokines TNF$\alpha$ and IL- 6 were significantly increased in lung homogenates from $\mathrm{SP}_{-} \mathrm{A}^{-/-}$compared with SP-A ${ }^{+/+}$mice (Figure 5). Three days after RSV infection, TNF- $\alpha$, IL6 , and MIP-2 levels were similar between SP-A ${ }^{-/-}$and $\mathrm{SP}-\mathrm{A}^{+/+}$mice (data not shown). IL-1 $\beta$ levels were similar at one day in $\mathrm{SP}_{-} \mathrm{A}^{-/-}$and SP-A ${ }^{+/+}$mice (Figure 5) but were significantly greater three days after RSV infection in the SP-A $\mathrm{A}^{-/}$mice (data not shown).

Decreased superoxide and bydrogen peroxide production by alveolar macrophages from $S P-A^{-1-}$ mice after RSV infection. Superoxide and hydrogen peroxide production was assessed in macrophages isolated from BAL fluid three days after intratracheal administration of RSV $\left(10^{6} \mathrm{pfu}\right)$. After stimulation with PMA, superoxide radical and hydrogen peroxide production by alveolar macrophages was significantly decreased in SP-A ${ }^{-/-}$compared with SP-A ${ }^{+/+}$mice (Table 1 ).

Exogenous SP-A increases viral clearance and decreases lung inflammation in $\mathrm{SP}-\mathrm{A}^{-/-}$mice. Three days after infection, the clearance of RSV in the SP-A ${ }^{-/}$mice was significantly enhanced when RSV was coadministered
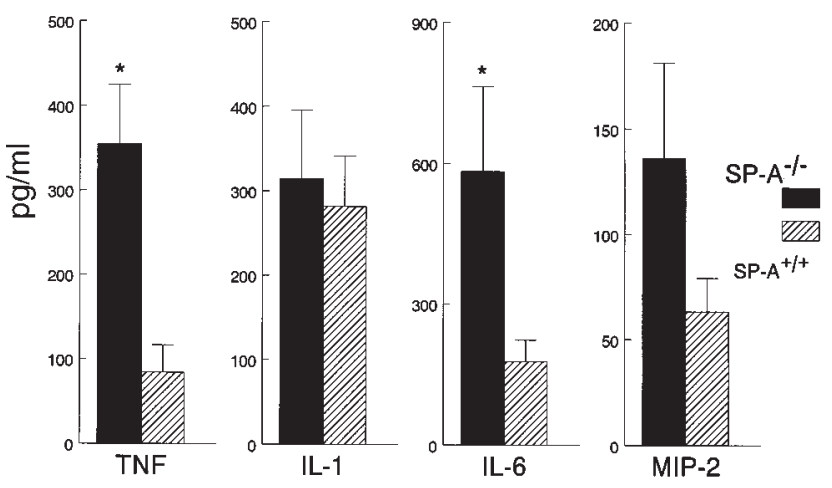

$24 \mathrm{~h}$

\section{Figure 5}

Increased tumor necrosis factor- $\alpha$ (TNF) and interleukin-6 (IL-6) in lung homogenates from SP-A ${ }^{-/-}$mice after RSV infection. Concentrations of TNF- $\alpha$, interleukin-1 $\beta$ (IL-1), IL-6, and macrophage inflammatory protein-2 (MIP-2) were assessed in lung homogenates from SP-A $\mathrm{A}^{-/-}$(filled bars) and $\mathrm{SP}_{-} \mathrm{A}^{+/+}$(hatched bars) mice. Increased concentrations of TNF- $\alpha$ and IL-6 were found in lung homogenates from the SP-A ${ }^{-/-}$mice at $24 \mathrm{~h}$. Although macrophage inflammatory MIP-2 was increased in SP-A $\mathrm{A}^{-/-}$at $24 \mathrm{~h}$, differences did not reach statistical significance. Data are expressed as picograms per milliliter and represent mean \pm SEM with $n=10$ mice per group. ${ }^{*} P<0.05$ compared with SP- $\mathrm{A}^{+/+}$mice. 

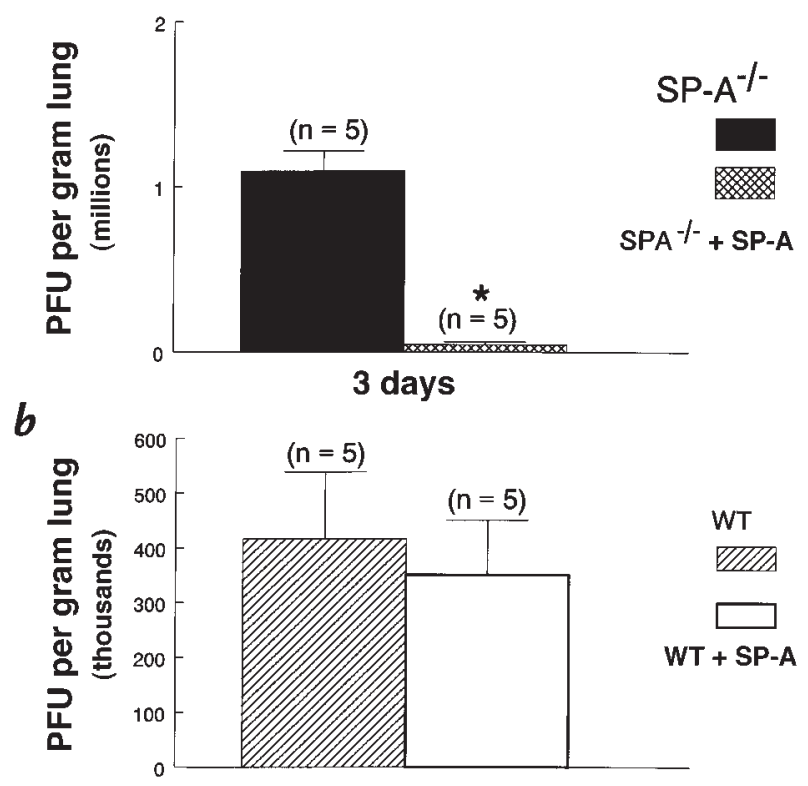

Figure 6

$\mathrm{SP}-\mathrm{A}$ enhanced RSV clearance from the lung of SP-A-/- mice. RSV titers were determined by quantitative plaque assays of lung homogenates 3 days after infection with $10^{7} \mathrm{pfu}$ of RSV. Viral titers in the lung were significantly reduced in SP-A ${ }^{-/-}$mice treated with SP-A $(100 \mu \mathrm{g})($ cross hatched bar) compared with untreated SP-A-/- mice (filled bar) (a). Treatment of SP-A ${ }^{-/-}$mice with SP-A reduced viral titers to the wild-type level. Viral titers were similar in SP-A-treated (open bar) and untreated wildtype mice (hatched bar) $(\boldsymbol{b})$. Data are mean \pm SEM. ${ }^{*} P<0.05$ compared with SP-A ${ }^{-/-}$mice. $W T$, wild-type.

with SP-A $(100 \mu \mathrm{g})$ (Figure 6). RSV clearance in SPA-treated SP-A $\mathrm{A}^{-/-}$mice was similar to that in $\mathrm{SP}_{-} \mathrm{A}^{+/+}$ mice. Treatment of SP-A ${ }^{+/+}$mice with a single dose of SP-A did not enhance viral clearance at three days (Figure 6). Total cell counts in BAL fluid one and three days after RSV infection were significantly reduced in the SP-A $/-$ mice treated with SP-A compared with untreated $\mathrm{SP}_{-} \mathrm{A}^{-/-}$mice. $\mathrm{SP}_{-} \mathrm{A}^{+/+}$mice treated with SP-A had similar cell counts in BAL fluid as did untreated

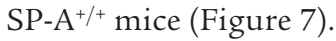

\section{Discussion}

Pulmonary clearance of intratracheally administered RSV was impaired in SP-A ${ }^{-/-}$compared with SP-A ${ }^{+/+}$ mice. Lung inflammation and viral titers were increased in the SP-A $\mathrm{A}^{-/}$mice, with decreased inflammation and enhanced clearance of the virus in $\mathrm{SP}_{-} \mathrm{A}^{-/-}$mice treated with exogenous SP-A. After RSV infection, superoxide radical and hydrogen peroxide production was markedly decreased in alveolar macrophages from SP-A $\mathrm{A}^{-/-}$mice. These findings support the concept that SP-A plays an important role in pulmonary host defense against RSV infection, mediated in part by increased alveolar macrophage oxygen radical production and viral killing.

Impaired clearance of RSV from the lung of SP- $\mathrm{A}^{-/-}$ mice supports the importance of SP-A in host defense. SP-A is a member of the C-type lectin family of polypeptides that includes mannose-binding protein, conglu- tinin, and SP-D. These proteins share structural features including collagenous $\mathrm{NH}_{2}$-terminal and "globular" $\mathrm{COOH}$-terminal, carbohydrate recognition domains, and all function as opsonins in vitro. In the presence of calcium, SP-A binds a variety of monosaccharides including D-mannose, L-fucose, D-glucose, and D-galactose (2). Adherence and phagocytosis of RSV may be mediated through the heavily glycosylated proteins on the viral surface, e.g., $\mathrm{F}$ protein and $\mathrm{G}$ protein, which may be recognized by the carbohydrate recognition domain of SP-A. Carbohydrate recognition by SP-A and opsonization of viruses may play an important role in the early clearance of viruses from the lungs. SP-A is expressed primarily in the respiratory epithelial cells and is hypothesized to play a role in protecting the lung from bacterial, viral, and fungal infections $(1,2)$. In vitro studies with herpes simplex virus type 1 as a model for virus phagocytosis revealed increased phagocytosis by alveolar macrophages in the presence of SP-A. When antibodies to SP-A were added to this in vitro system, the phagocytosis of herpes simplex virus by macrophages was abolished (16). The addition of SP-A to cell cultures infected with influenza A virus resulted in a reduction of viral infected cells (18), and SPA enhanced the association of influenza $A$ virus with alveolar macrophage in a dose-dependent manner (19). Deglycosylated SP-A did not bind viral infected cells, suggesting that the carbohydrate moiety of SP-A is involved in the recognition of viruses by SP-A $(17,18)$. The current study demonstrates impaired clearance of RSV from the lung in the absence of SP-A in vivo.

Infiltration of neutrophils after RSV administration was more intense in $\mathrm{SP}_{-} \mathrm{A}^{-/-}$then in $\mathrm{SP}_{-} \mathrm{A}^{+/+}$mice. Enhanced neutrophil chemotaxis may have resulted from the increased cytokine production in the lungs of the SP$\mathrm{A}^{-/-}$mice. MIP-2, a neutrophil chemoattractant, was elevated consistent with increased neutrophils in $\mathrm{SP}_{-} \mathrm{A}^{-/}$ BAL fluid. PMNs are able to adhere to RSV-infected

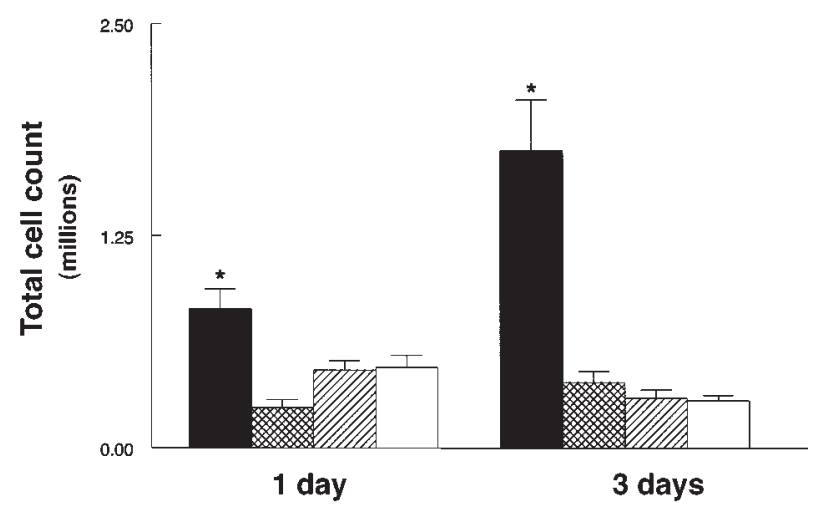

Figure 7

SP-A decreased inflammatory cells in BAL fluid from SP-A $\mathrm{A}^{-/-}$mice. After RSV infection ( $\left.10^{7} \mathrm{pfu}\right)$, lung cells were recovered by BAL, stained with trypan blue, and counted under light microscopy. One and 3 days after RSV infection, total cell counts in BAL fluid were significantly reduced in SP-A ${ }^{-/-}$mice treated with SP-A $(100 \mu \mathrm{g})$ (cross-hatched bars) compared with untreated SP-A $\mathrm{A}^{-1-}$ mice (filled bars). Treatment of SP-A ${ }^{-1-}$ mice reduced $B A L$ cell counts to the wild-type level (hatched bars). Total cell counts in BAL fluid were similar in SP-A-treated (open bars) and untreated wild-type mice (hatched bars). Data are mean \pm SEM. ${ }^{*} P<0.05$ compared with $\mathrm{SP}-\mathrm{A}^{+/+}$mice. 
epithelial cells (38). SP-A $\mathrm{A}^{-/-}$mice had greater viral titers in the lung, which may provide increased binding sites for PMNs. In vitro, macrophages infected with RSV have increased TNF- $\alpha$ and increased IL- 6 mRNA and protein production (39). TNF- $\alpha$ has been shown to have antiviral activity in vitro (40); however, in the present in vivo model, viral clearance was impaired in $\mathrm{SP}_{-} \mathrm{A}^{-/}$mice despite increased TNF- $\alpha$. RSV is known to be a poor inducer of IL-1 compared with viruses like parainfluenza and influenza (41). These data are consistent with the present study, demonstrating similar IL-1 levels in $\mathrm{SP}_{-} \mathrm{A}^{-/}$and SP$\mathrm{A}^{+/+}$mice despite increased viral titers in $\mathrm{SP}_{-} \mathrm{A}^{-/-}$mice. The role of SP-A and cytokine production in vitro is controversial. SP-A stimulated TNF- $\alpha$, IL-1, and IL- 6 production by mononuclear cells (42). In contrast, McIntosh et al. (43) reported that SP-A blunted TNF- $\alpha$ release from lipopolysaccharide-stimulated macrophages. The present finding that cytokine production was more modest in SP$\mathrm{A}^{+/+}$than in $\mathrm{SP}-\mathrm{A}^{-/-}$mice in vivo supports the McIntosh et al. study, suggesting that SP-A decreases the release of cytokines in response to viral infection. It is unclear from the present study whether the alveolar macrophages and/or respiratory epithelium have enhanced production of inflammatory cytokines in the absence of SP-A.

Phagocytic cells generate reactive oxygen species that are involved in viral killing. Phagocytosis of invading microorganisms leads to increased oxygen consumption and to reduction of oxygen to superoxide, which is then secreted into the phagosome, where it dismutates to hydrogen peroxide. Production of superoxide and hydrogen peroxide contributes to microbial killing. In the current study, stimulated macrophages from SP-A ${ }^{-/}$mice generated less superoxide and hydrogen peroxide than did SP-A $\mathrm{A}^{+/+}$macrophages, demonstrating a critical role of SP-A in oxidant production. Differences in oxygen radical production may not, however, be directly related to RSV infection, as the macrophages were stimulated with PMA. Decreased production of superoxide by macrophages from SP-A ${ }^{-/-}$mice was also demonstrated previously during bacterial infection (35). In vitro, SP-A enhanced lucigenin-dependent chemiluminescence of rat alveolar macrophages (12), indicating that SP-A may stimulate the release of superoxide radicals to enhance bacterial killing. Other studies, however, failed to demonstrate effects of SP-A on intracellular killing of bacteria by monocytes; and SP-A-opsonized S. aureus did not induce the production of reactive oxygen intermediates (44). Superoxide and hydrogen peroxide production by alveolar macrophages from $\mathrm{SP}_{-} \mathrm{A}^{-/-}$mice was decreased compared with SP-A ${ }^{+/+}$mice. Influenza viruses, paramyxoviruses, and the hepatitis $\mathrm{B}$ virus have been shown to activate monocytes and polymorphonuclear leukocytes in vitro to generate reactive oxygen species (28). The current study suggests that SP-A may enhance RSV killing through macrophage activation and production of reactive oxygen species.

Viral titers of RSV in the lung were greater in the SP$\mathrm{A}^{-/-}$mice; however, coadministration of RSV with SP-A enhanced clearance and decreased inflammation from lungs of SP-A ${ }^{-/}$mice to the level of SP-A ${ }^{+/+}$mice. The total pool of SP-A in the lung is found in the macrophage, tissue compartment, and alveolar fluid.
Administration of exogenous SP-A may increase the free SP-A available to enhance viral clearance. Treatment of wild-type mice with SP-A did not enhance clearance or decrease inflammation in the lung, suggesting that wildtype levels of SP-A are sufficient to clear the injected dose of RSV. During lung injury, changes in the concentration of surfactant proteins may be caused by changes in SP-A synthesis or degradation. SP-A levels are reduced in BAL fluid from children with respiratory failure due to RSV (22). The present study supports the concept that low levels of SP-A reduce RSV clearance, leading to enhanced inflammation.

In summary, the present study demonstrates a role of SP-A in pulmonary clearance of RSV in vivo. RSV clearance was associated with an enhanced respiratory burst by the alveolar macrophage. Because the airway is usually the portal of entry for RSV and other respiratory pathogens, local production of SP-A is likely to play a role in innate defenses preventing pneumonia. SP-A concentrations are decreased in preterm infants (25) and in primates with bronchopulmonary dysplasia (24), conditions that may influence susceptibility to RSV infection and inflammation. Exogenous administration of SP-A enhanced clearance of RSV and decreased inflammation in the SP-A $\mathrm{A}^{-/-}$mice and, therefore, may represent a strategy to prevent or treat RSV pulmonary infections.

\section{Acknowledgments}

We thank Barney Graham for providing the RSV stocks, Jaymi Semona for assistance with animal production, and Peter Gartside for assistance with statistical methods. Supported by National Institutes of Health grants HL 28623, HL 58795, and HL 03905 and by The Cystic Fibrosis Foundation.

1. Thiel, S., and Reid, K. 1989. Structures and functions associated with the group of mammalian lectins containing collagen-like sequences. FEBS Lett. 250:78-84.

2. Sastry, K., and Ezekowitz, R.A. 1993. Collectins: pattern recognition molecules involved in first line host defense. Curr. Opin. Immunol. 5:59-66.

3. Super, M., Thiel, S., Lu, J., Levinsky, R.J., and Turner, M.W. 1989. Association of low levels of mannan-binding protein with a common defect of opsonisation. Lancet. 2:1236-1239.

4. Malhotra, R., Thiel, S., Reid, K.B., and Sim, R.B. 1990. Human leukocyte $\mathrm{C} 1 \mathrm{q}$ receptor binds other soluble proteins with collagen domains. J. Exp. Med. 172:955-959.

5. Friis-Christiansen, P., et al. 1990. In vivo and in vitro antibacterial activity of conglutinin, a mammalian plasma lectin. Scand. J. Immunol. 31:453-460.

6. Ezekowitz, R.A.B., Kuhlman, M., Groopman, J.E., and Byrn, R.A. 1989. A human serum mannose-binding protein inhibits in vitro infection by the human immunodeficiency virus. J. Exp. Med. 169:185-196.

7. McNeely, T.B., and Coonrod, J.D. 1993. Comparison of the opsonic activity of human surfactant protein A for Staphylococcus aureus and Streptococcus pneumoniae with rabbit and human macrophages. J. Infect. Dis. 167:91-97.

8. Kuan, S.F., Rust, K., and Crouch, E. 1992. Interactions of surfactant protein D with bacterial lipopolysaccharides. J. Clin. Invest. 90:97-106.

9. Pison, U., Wright, J.R., and Hawgood, S. 1992. Specific binding of surfactant apoprotein SP-A to rat alveolar macrophages. Am. J. Physiol. 262:L412-L417.

10. Wright, J.R., Borchelt, J.D., and Hawgood, S. 1989. Lung surfactant apoprotein SP-A $(26-36 \mathrm{kDa})$ binds with high affinity to isolated alveolar type II cells. Proc. Natl. Acad. Sci. USA. 86:5410-5414.

11. Wright, J.R., and Youmans, D.C. 1993. Pulmonary surfactant protein A stimulates chemotaxis of alveolar macrophages. Am. J. Physiol. 264:L338-L344.

12. van Iwaarden, F., Welmers, B., Verhoef, J., Haagsman, H.P., and van Golde, L.M.G. 1990. Pulmonary surfactant protein A enhances the hostdefense mechanism of rat alveolar macrophages. Am. J. Respir. Cell Mol. Biol. 2:91-98.

13. Manz-Keinke, H., Plattner, H., and Schlepper-Schafer, J. 1992. Lung surfactant protein A (SP-A) enhances serum-independent phagocytosis of bacteria by alveolar macrophages. Eur. J. Cell Biol. 57:95-100. 
14. McNeely, T.B., and Coonrod, J.D. 1994. Aggregation and opsonization if type A but not type B Hemophilus influenzae by surfactant protein A. Am. J. Respir. Cell Mol. Biol. 11:114-122.

15. Pascula, R., et al. 1997. Surfactant protein A (SP-A) mediates attachment of Mycobacterium tuberculosis to murine alveolar macrophages. Am. J. Respir. Cell Mol. Biol. 17:209-217.

16. van Iwaarden, J.F., et al. 1991. Surfactant protein A is opsonin in phagocytosis of herpes simplex virus type 1 by rat alveolar macrophages. Am. J. Physiol. 261:L204-L209.

17. van Iwaarden, J.F., et al. 1992. Binding of surfactant protein A (SP-A) to herpes simplex virus type 1 -infected cells is mediated by the carbohydrate moiety of SP-A. J. Biol. Chem. 267:25039-25043.

18. Benne, C.A., et al. 1995. Interactions of surfactant protein A with influenza A viruses: binding and neutralization. J. Infect. Dis. 171:335-341.

19. Benne, C.A., Benaissa-Trouw, B., van Strijp, J.A.G., Kraaijeveld, C.A., and van Iwaarden, J.F.F. 1997 Surfactant protein A, but not surfactant protein $\mathrm{D}$, is an opsonin for influenza A virus phagocytosis by rat alveolar macrophages. Eur. J. Immunol. 27:886-890.

20. Kim, H.W., et al. 1973. Epidemiology of respiratory syncytial virus infection in Washington, D.C. Am. J. Epidemiol. 98:216-225.

21. Green, M., Brayer, A.F., Schenkman, K.A., and Wald, E.R. 1989. Duration of hospitalization in previously well infants with respiratory syncytial virus infection. Pediatr. Infect. Dis. J. 8:601-605.

22. LeVine, A.M., et al. 1996. Surfactant content in children with inflammatory lung disease. Crit. Care Med. 24:1062-1067.

23. Dargaville, P.A., South, M., and McDougall, P.N. 1996. Surfactant abnormalities in infants with severe viral bronchiolitis. Arch. Dis. Child. 75:133-136

24. Coalson, J.J., et al. 1995. SP-A deficiency in a primate model of bronchopulmonary dysplasia with infection. Am. J. Respir. Crit. Care Med. 151:854-866.

25. Gerdes, J.S., Abbasi, S., Karp, K., Hull, W., and Whitsett, J.A. 1990. Surfactant protein-A in bronchoalveolar lavage fluid from neonates with RDS on conventional and high-frequency oscillatory ventilation. Pediatr. Pulmonol. 9:166-169.

26. Griese, M., Birrer, P., and Demirsoy, A. 1997. Pulmonary surfactant in cystic fibrosis. Eur. Respir. J. 10:1983-1988.

27. Kimpen, J.L.L., and Heymans, H.S.A. 1993. Respiratory syncytial virus: immunity and immune injury. Immunol. Infect. Dis. 3:281-288.

28. Schwarz, K.B. 1996. Oxidative stress during viral infection: a review. Free Radic. Biol. Med. 21:641-649.

29. Weissbach, S., Neuendank, A., Pettersson, M., Schaberg, T., and Pison, U. 1994. Surfactant protein A modulates release of reactive oxygen species from alveolar macrophages. Am. J. Physiol. 267:L660-L666.

30. Weber H., Heilmann, P., Meyer, B., and Maier, K.L. 1990. Effect of canine surfactant protein (SP-A) on the respiratory burst of phagocytic cells. FEBS Lett. 270:90-94.

31. LeVine, A.M., et al. 1997. Surfactant protein A-deficient mice are susceptible to group B streptococcal infection. J. Immunol. 158:4336-4340.

32. LeVine, A.M., et al. 1998. Surfactant protein-A deficient mice are susceptible to Pseudomonas aeruginosa infection. Am. J. Respir. Cell Mol. Biol. 19:700-708

33. Korfhagen, T.R., et al. 1996. Altered surfactant function and structure in SP-A gene targeted mice. Proc. Natl. Acad. Sci. USA. 93:9594-9599.

34. Haagsman, H.P., et al. 1987. The major surfactant protein, SP-A 28-36, is a calcium-dependent carbohydrate-binding protein. J. Biol. Chem. 262:13877-13880.

35. LeVine, A.M., et al. 1999. Surfactant protein-A (SP-A) binds group B streptococcus, enhancing phagocytosis and clearance from lungs of SPA deficient mice. Am. J. Respir. Cell Mol. Biol. 20:279-286.

36. Sedgwick, J.B., Vrtis, R.F., Gourley, M.F., and Busse, W.W. 1988. Stimulus-dependent differences in superoxide anion generation by normal human eosinophils and neutrophils. J. Allergy Clin. Immunol. 81:876-883.

37. Graham, B.S., Perkins, M.D., Wright, P.F., and Karzon, D.T. 1988. Primary respiratory syncytial virus infection in mice. J. Med. Virol. 26:153-162.

38. Faden, H., Hong, J.J., and Ogra, P.L. 1984. Interaction of polymorphonuclear leukocytes and viruses in humans: adherence of polymorphonuclear leukocytes to respiratory syncytial virus-infected cells. J. Virol. 52:16-23.

39. Becker S., Quay, J., and Soukup, J. 1991. Cytokine (tumor necrosis factor, IL-6 and IL-8) production by respiratory syncytial virus-infected human alveolar macrophages. J. Immunol. 147:4307-4312.

40. Merolla, R., Rebert, N.A., Tsiviste, P.T., Hoffmann, S.P., and Panuska, J.R. 1995. Respiratory syncytial virus replication in human lung epithelial cells: inhibition by tumor necrosis factor $\alpha$ and interferon $\beta$. Am.J. Respir. Crit. Care Med. 152:1358-1366.

41. McCarthy, D.O., Domurat, F.M., Nichols, J.E., and Roberts, N.J., Jr. 1989. Interleukin-1 inhibitor production by human mononuclear leukocytes and leukocyte subpopulations exposed to respiratory syncytial virus: analysis and comparison with the response to influenza virus. J. Leukoc. Biol. 46:189-198.

42. Kremlev, S.G., and Phelps, D.S. 1994. Surfactant protein A stimulation of inflammatory cytokine and immunoglobulin production. Am. J. Physiol. 267:L712-L719.

43. McIntosh, J.C., Mervin-Blake, S., Conner, E., and Wright, J.R. 1996. Surfactant protein A protects growing cells and reduces TNF- $\alpha$ activity from LPS-stimulated macrophages. Am. J. Physiol. 271:L310-L319.

44. Geertsma, M.F., Nibbering, P.H., Haagsman, H.P., Daha, M.R., and Van Furth, R. 1994. Binding of surfactant protein A to C1q receptors mediates phagocytosis of Staphylococcus aureus by monocytes. Am. J. Physiol. 267:L578-L584. 